\title{
A New Charge-Associated Mechanism to Account for the Production of Fragment Ions in the High-Energy CID Spectra of Fatty Acids
}

\author{
David J. Harvey \\ Department of Biochemistry, Oxford Glycobiology Institute, Oxford, United Kingdom
}

A new mechanism, termed a charge-assisted process, is proposed as an additional mechanism to the charge-remote process to account for ions of the $\left[\mathrm{M}-\mathrm{C}_{n} \mathrm{H}_{2 n+2}\right]$ series found in the positive and negative high energy CID spectra of fatty acids and related compounds when ionized as closed-shell $\left([\mathrm{M}-\mathrm{H}]^{-}\right.$or $\left.[\mathrm{M}+\mathrm{X}]^{+}\right)$species. The new mechanism is based on that commonly invoked to account for similar ions in the electron-impact spectra of derivatized fatty acids whereby the positive charge on the derivative abstracts a hydrogen atom from various positions of the alkyl chain to leave a radical that initiates a radical-induced cleavage of the chain. It is proposed that in the high energy CID spectra of closed-shell ions, similar hydrogen migrations occur but unpairing of electrons is avoided by charge transfer to the alkyl chain. This charge then initiates a concerted cleavage of the chain to give an allylic carbonium (positive ion spectrum) or carbanion (negative ion spectrum). The mechanism avoids the need to involve radicals or loss of hydrogen atoms from even-electron (closed shell) ions and provides a driving force for the reaction, namely, the formation of ions with a stabilized charge. An extension of the mechanism is also proposed to account for the formation of odd-electron ions from these compounds. The charge-assisted mechanism does not rule out the occurrence of other mechanisms that have been accepted for many years but provides an alternative process that can account for some spectral features which were difficult to explain earlier. (J Am Soc Mass Spectrom 2005, 16, 280-290) (c) 2004 American Society for Mass Spectrometry

$\mathrm{E}$ lectron impact (EI) induced fragmentation of fatty acids and their alkyl esters generally provides little information on the structure of the alkyl chain as fragmentation is localized around the acidic moiety. Furthermore, the double bonds of unsaturated acids tend to migrate under these conditions, precluding positional determination. For structural determination of unsaturated compounds, several approaches such as chemical derivatization of the bond(s) $[1,2]$ and the use of nitrogen-containing derivatives, such as 2-alkenylbenzoxazoles [3], pyrrolidides [4-8], 2-alkylimidazolines [9], or picolinyl esters [10-13] have been used to overcome the bond migration problem. These nitrogen-containing derivatives capture the electronic charge [14] and initiate hydrogen abstraction from random positions of the chain to produce radicalinduced cleavages at each carbon-carbon bond. The resulting spectra contain a series of ions, the mass and relative abundance of which reveals the chain structure.

Positive ions from fatty acids or their derivatives

Published online January 7, 2005

Address reprint requests to Dr. D. J. Harvey, Department of Biochemistry, Oxford Glycobiology Institute, South Parks Road, Oxford OX1 3QU, United Kingdom. E-mail: dh@glycob.ox.ac.uk adducted with alkali- [15-28] and alkaline-earth [29] metals and both positive [30-32] and negative ions [16, 33-41] formed from these or related compounds [21] by fast atom bombardment (FAB) or electrospray ionization, are even-electron species and would not be expected to fragment by such radical-induced mechanisms. Yet, their high energy CID spectra (Figure 1) show remarkable similarities with those of their oddelectron counterparts produced by EI [18, 22, 23, 28, 42]. The major fragment ions in these high energy CID spectra are even-electron (closed shell) species belonging to the $\left[\mathrm{M}-\mathrm{C}_{\mathrm{n}} \mathrm{H}_{2 \mathrm{n}+2}\right]$ series but also present, depending on the ionization conditions and internal energy of the ions, are other series, predominantly of the composition [M $-\mathrm{C}_{\mathrm{n}} \mathrm{H}_{2 \mathrm{n}+1}$ ] [41] that have odd numbers of electrons and must be radicals. Hydrogen atom loss has frequently been proposed to account, not only for this ion series, but to be involved in the formation of the major, closed-shell $\mathrm{C}_{\mathrm{n}} \mathrm{H}_{2 \mathrm{n}+2}$ ion series $[23,28]$ even though such a mechanism involves the energetically unfavorable unpairing of electrons.

Much of the fragmentation of the high energy, evenelectron CID ions has been rationalized by charge-remote mechanisms of the type first proposed by Gross and co-workers in the 1980s [33, 43-45]. Thus, Jensen et al. [33] 


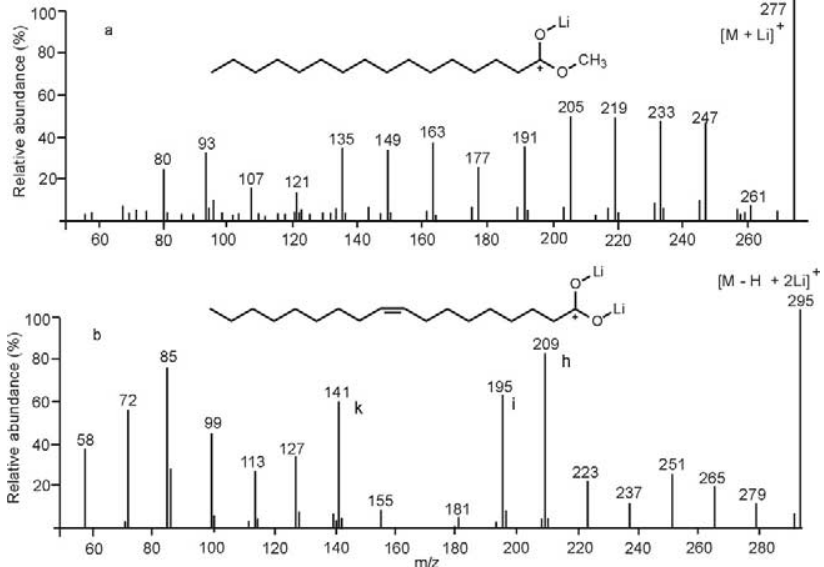

Figure 1. High energy CID spectra of the lithium adducts of (a) the methyl ester of hexadecanoic acid (16:0) and (b) $\Delta^{9}$-octadecenoic acid (18:1) (redrawn from Antoine and Adams [36]).

envisaged a 1,4-dihydrogen elimination with the formation of two unsaturated species (Scheme 1) whereas Wysocki and Ross [46] and others [39] have proposed a homolytic carbon-carbon bond cleavage with the formation of radicals. Radical formation is also implicated in mechanisms proposed by Claeys et al. [22, 23, 28] which again involves hydrogen atom elimination and unpairing of electrons.

Several points are evident when the spectra of fatty acids and the mechanisms proposed to account for the formation of their fragment ions are examined:

1. Many of the mechanisms proposed for evenelectron ions involve the thermodynamically unfavorable formation of free radical species, many of which do not appear to offer any increase in stability. Often the reverse is true.

2. The fragmentation spectra recorded from evenelectron species show a remarkable similarity to the spectra recorded from odd-electron ions produced by EI from derivatized fatty acids and where fragmentation can be accounted for by hydrogen migration from the aliphatic chain to the initial charge site on the derivative and a subsequent radical-induced cleavage of the chain. This similarity suggests the existence of a comparable fragmentation mechanism occurring in even-electron species and supporting the concept of a charge-site rather than a remote-site fragmentation process.

3. Deuterium labeling results from several laboratories, particularly from experiments performed using electron impact, indicate the existence of extensive hydrogen migrations and scrambling during fragmentation of many long-chain compounds [47-50]. Hydrogen migrations are also implicated in the fragmentation of some even-electron ions such as those produced by FAB [17, 18, 25].

These observations lead to the conclusion that many of the mechanisms proposed to account for fragment ions in the high energy MS/MS spectra of closed shell ions from fatty acids do not account fully for the fragmentation patterns seen. This paper proposes an alternative fragmentation mechanism, based on a charge-associated process which avoids the need to propose the uncoupling of electrons to form unstable free radicals and accommodates the suggested involvement of the charge and the frequently observed hydrogen migrations. Such a mechanism can account for many of the ions found in the high-energy CID spectra of various fatty acid types, as discussed below, and accounts for several features of the spectra that were difficult to explain earlier.

Proposed involvement of the charge in such reactions is not new and was suggested by Wysocki and Ross [46] in one of the early studies in this area. Furthermore, Contado et al. [19] noted that, for unsaturated fatty acids containing the double bond towards the middle of the chain, charge-remote fragmentations involving allylic bond fission should be equally probable on either side of the double bond. Such behavior is not seen, suggesting that the charge has some, but unspecified, influence on the fragmentation. Antoine and Adams [36] noted that the fragmentation spectra of $[\mathrm{M}-\mathrm{H}+2 \mathrm{Cat}]^{+}$, where Cat is an alkali metal, depended on the nature of the alkali metal, also suggesting charge involvement. Other investigators have noted similar phenomena [26, 28].

\section{Charge-Assisted Fragmentation}

It is apparent from the spectra reported in the literature that several processes are involved in the fragmentation of fatty acids and their derivatives [46, 51]. Both even (closed shell) and odd electron species are produced from closed-shell precursors, the relative abundance of which depends on factors such as ion energy and ion lifetime.

\section{Saturated Carboxylic Acids}

The new mechanism, termed a "charge-assisted" process, proposes the transfer of a hydrogen as $\mathrm{H}^{-}$or $\mathrm{H}^{+}$, depending on the nature of the spectrum, from the aliphatic chain to the charge site at the carboxyterminus in an analogous manner to that proposed for the transfer of a hydrogen atom $(\mathrm{H})$ to account for the fragment ions in the EI spectra of derivatized acids [11]. However, rather than a hydrogen atom (one electron) being involved with the net transfer of the radical site to the aliphatic chain, the proposed mechanism envisages transfer of a hydrogen with two (positive ion) or zero (negative ion) electrons (Scheme 2) to the carboxy

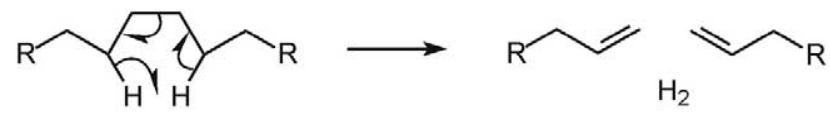

Scheme 1. 1,4-hydrogen elimination proposed for the charge remote fragmentation of aliphatic chains. 


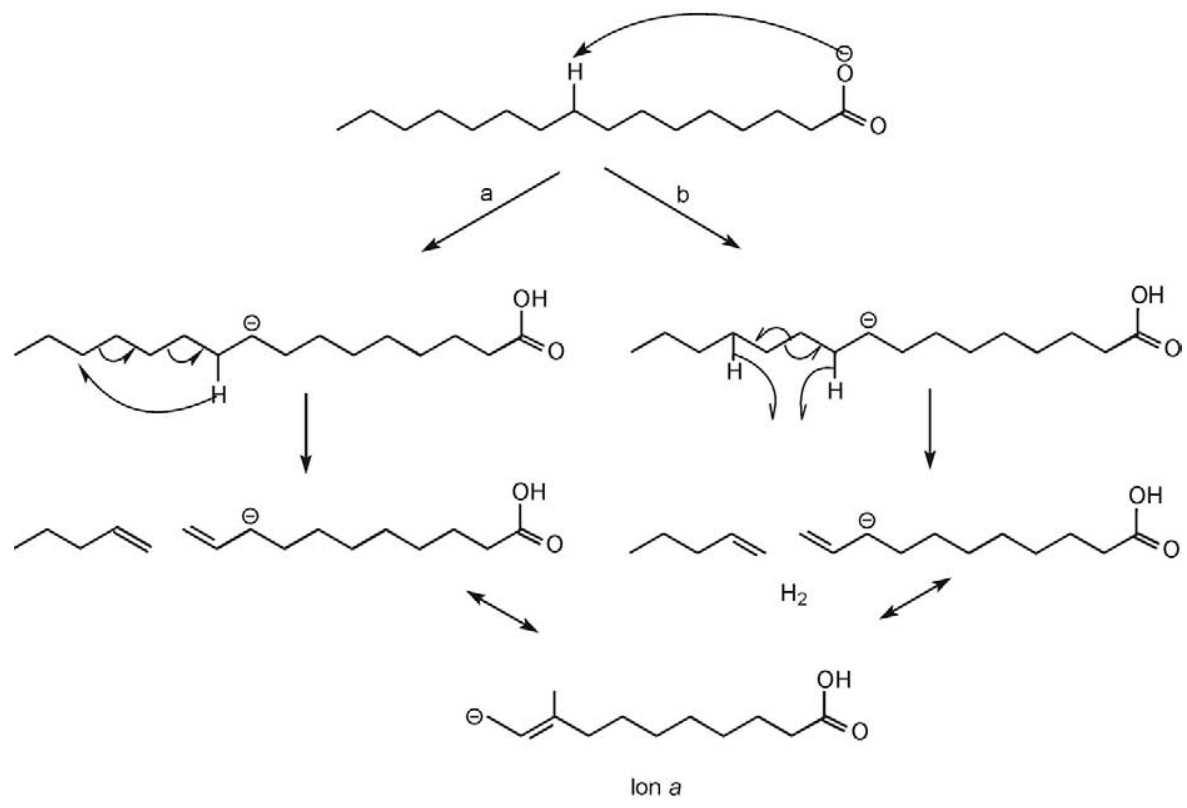

Scheme 2. Proposed mechanisms for the formation of ions of the $\left[M-C_{n} H_{2 n+2}\right]$ series shown for the $[\mathrm{M}-\mathrm{H}]^{-}$ion from hexadecanoic (palmitic) acid.

terminus. Because the recipient oxygen atom assumes its normal valency, further electron migration of the McLafferty-type would not be expected to occur. The result, therefore, is transfer of the charge to the site of hydrogen loss from the aliphatic chain and no further cleavage at the carboxy terminus. This charge then promotes a concerted rearrangement, either to release a hydrogen molecule and an alkene in a 1,4-hydrogen rearrangement of the type proposed by Gross et al. (Scheme 2, Path b), or to release an alkane and ethylene (Scheme 2, Path a). In either case, a double bond is formed in the ionic fragment such that the charge is stabilized by resonance (Scheme 2, Ion a). The intermediate structure is of comparable stability to that of the parent ion (bond energies from [52]) and is, thus, formed in preference to radicals that require considerable energy to cleave the $\mathrm{C}=\mathrm{C}$ or $\mathrm{C}-\mathrm{H}$ bonds. Once formed, the intermediate fragments to form the resonance-stabilized product ion, thus providing the driving force for the reaction. Not only does this mechanism account for the series of ions seen in the high energy spectrum (initiated by hydrogen migration from various sites in the chain), it also explains many of the differences in relative abundance of these ions reported by several investigators and which are difficult to account for by existing theories.

\section{Negative Ions of the $\left[M-\mathrm{C}_{n} \mathrm{H}_{2 n+2}\right]^{-}$Series}

The negative ion, high-energy CID spectra of the anions from long-chain fatty acids, such as octadecanoic (stearic) acid shown by Griffiths et al. [40] (Figure 2), exhibit a series of $\left[\mathrm{M}-\mathrm{C}_{\mathrm{n}} \mathrm{H}_{2 \mathrm{n}+2}\right]^{-}$ions at $\mathrm{m} / \mathrm{z} 99,113,127,141,155,169,183,197,211,225$, and 239. A similar series is sometimes present in the low energy spectra but at a very low and structurally insignificant abundance. The existence of a purely charge-remote mechanism for cleavage of the aliphatic chain would predict comparable fragmentation at each $\mathrm{C}-\mathrm{C}$ bond although this is not seen for cleavages near to the carboxy terminus: the relative abundance of the ion at $\mathrm{m} / \mathrm{z} 99$ is low, and the predicted ion at $\mathrm{m} / \mathrm{z} 85$ is missing. The ion at $\mathrm{m} / \mathrm{z} 71$ appears to be formed by a different mechanism.

Evidence from neutralization-reionization mass spectrometry of the neutral particles eliminated in fragmentation of saturated fatty acids obtained by

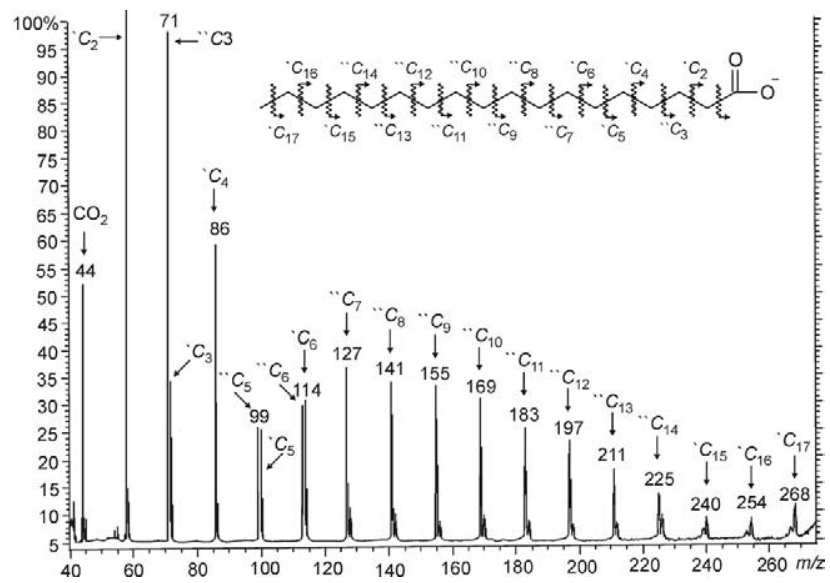

Figure 2. $400 \mathrm{eV}$ CID Spectrum of the anion from octadecanoic (stearic) acid. Ions are labeled as described by Griffiths et al. A superscript prime indicates loss of one hydrogen atom and two superscript primes indicate loss of two hydrogens. Thus the [M $\mathrm{C}_{n} \mathrm{H}_{2 n+2}$ ] ions are indicated by " $\mathrm{C}_{\mathrm{x}}$ where $\mathrm{C}$ represents $\mathrm{C}-\mathrm{C}$ bond cleavage and $\mathrm{x}$ is the position of cleavage relative to the carboxy function (redrawn from Griffiths et al. [40]). 

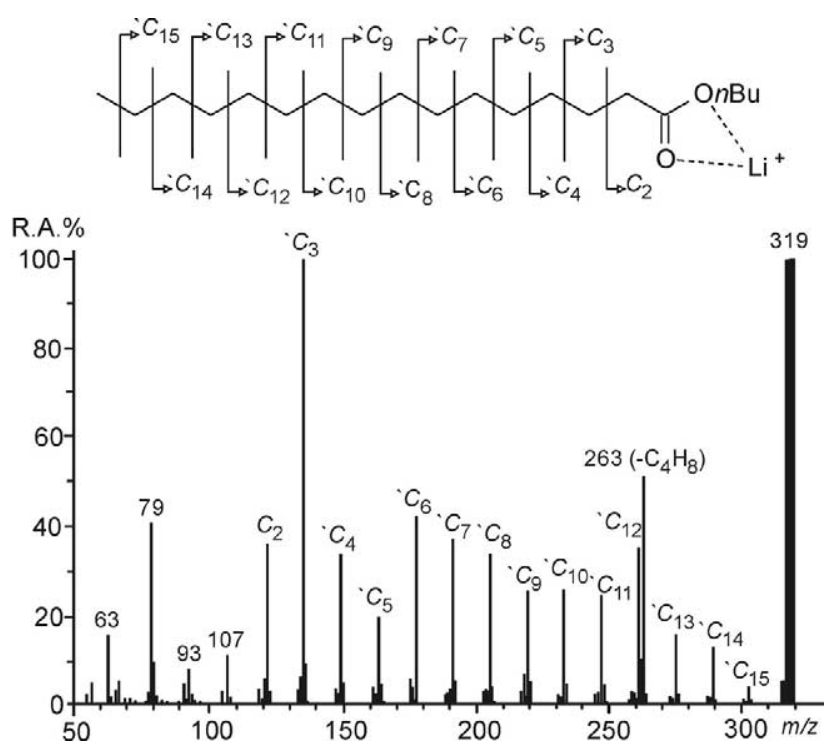

Figure 3. High energy CID spectra of the $[\mathrm{M}+\mathrm{Li}]^{+}$ion from the butyl ester of hexadecanoic (palmitic) acid. Because ionization does not involve loss of a proton, as with the negative ion spectra, the $\left[\mathrm{M}-\mathrm{C}_{\mathrm{n}} \mathrm{H}_{2 \mathrm{n}+2}\right]^{+}$ion series only involves loss of one hydrogen atom and is labeled with a single prime, as in the original paper (redrawnéfroméClaeyséetéal.ê[22].

Cordero and Wesdemiotis [53] suggests that the 1,4-dihydrogen elimination of the type shown in Scheme 2, Pathway b, is dominant as all of the low mass ions identified in their experiments were alkenes rather than alkanes. However, the spectra of the long-chain fatty acids and their derivatives substituted with deuterium on the alkyl chain suggest otherwise. Fragmentation involving cleavage of a deuterium atom would be expected to show a primary kinetic isotope effect. The mechanism shown in Scheme 2, Pathway a, involves cleavage of one $\mathrm{C}-\mathrm{H}$ bond and thus, only one of the ions of the $\mathrm{C}_{n} \mathrm{H}_{2 n+2}$ series normally seen in the high-energy spectra should show an isotope effect. Such an effect is clearly seen for the lithium adduct of $\left[9,9-{ }^{2} \mathrm{H}_{2}\right]-n$ butyl palmitate reported by Claeys et al. [22] for cleavage of the $\mathrm{C} 10-\mathrm{C} 11$ bond, as predicted. If the 1,4-hydrogen elimination were to occur, as in Scheme 2, Pathway b, or in a remote-site fragmentation, cleavage of the C7-C8 bond would also be expected to show an isotope effect. However, no such effect is observed supporting a mechanism of the type shown in Pathway a. However, as the existence of the generally accepted 1,4-elimination cannot be ruled out, subsequent fragmentation schemes in this paper will show both mechanisms.

It is proposed that formation of the resonancestabilized product ion (a) by a charge-assisted mechanism following a hydrogen migration to the carboxyanion is the driving force for the reaction forming the $\left[\mathrm{M}-\mathrm{C}_{\mathrm{n}} \mathrm{H}_{2 \mathrm{n}+2}\right]$ ions in both positive and negative ion modes. The mechanism is consistent with the results from other reported deuterium-labeling experiments $[22,23]$ that support loss of a hydrogen atom from the penultimate position of the alkyl chain of the fragment ion and formation of an ion with a terminal double bond. An alternative process in which this double bond could be formed to the initial site of hydrogen movement can be discounted because stable isotope labeling experiments show that the hydrogen atom cleaved from the penultimate carbon atom of the product is eliminated rather than transferred to a different position within the same ion. Thus, the hydrogen that originally migrated to the carboxy terminus cannot originate from one of the carbon atoms ultimately involved in formation of the double bond.

Migration of hydrogen atoms to the carboxy terminus of fatty acid ions leave a charge or radical on the alkyl chain, as implicated here, has been proposed before to account for various features in their mass spectra, Thus, for example, the absence of a McLafferty rearrangement in the EI-CID spectra of fatty acid methyl esters [54]éhasébeenéattributedétoéaérearrangement involving transfer of a hydrogen atom from the alkyl chain to the carboxy function to leave a molecular ion with a radical site on the chain. Subsequent fragmentation of this ion gave fragments initiated from this radical site rather than those produced by a McLafferty rearrangement.éLaprévoteéetéal.é[55]éhaveéproposed similar long-range hydrogen migrations to explain the formation of an ion at $\mathrm{m} / \mathrm{z} 252$ that moved to $\mathrm{m} / \mathrm{z} 254$ in the spectrum of the lithium adduct of $\left[18,18,18-{ }^{2} \mathrm{H}_{3}\right]-$ stearicéacid,éandéVoinovéandéClaeysé[56]éhaveéimpli-

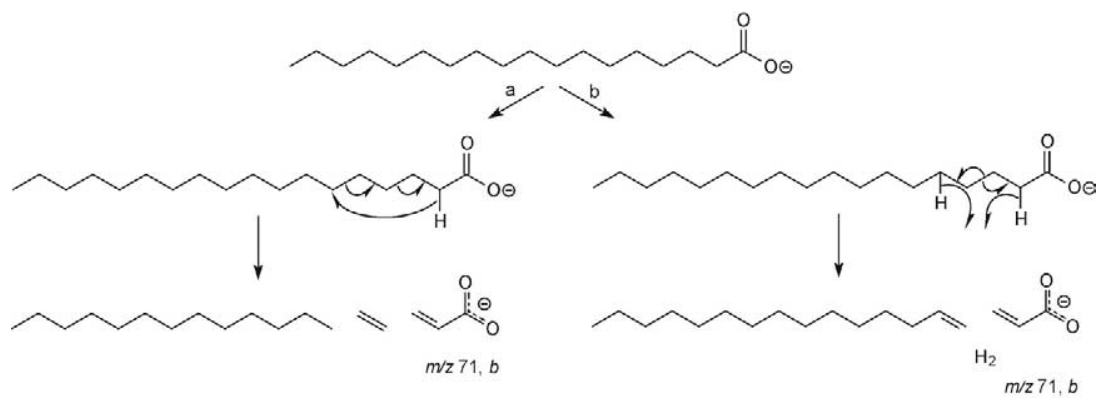

Scheme 3. Proposed mechanisms for the formation of the ion at $m / z 71$ in the high energy negative ion CID mass spectrum of octadecanoic (stearic) acid. 


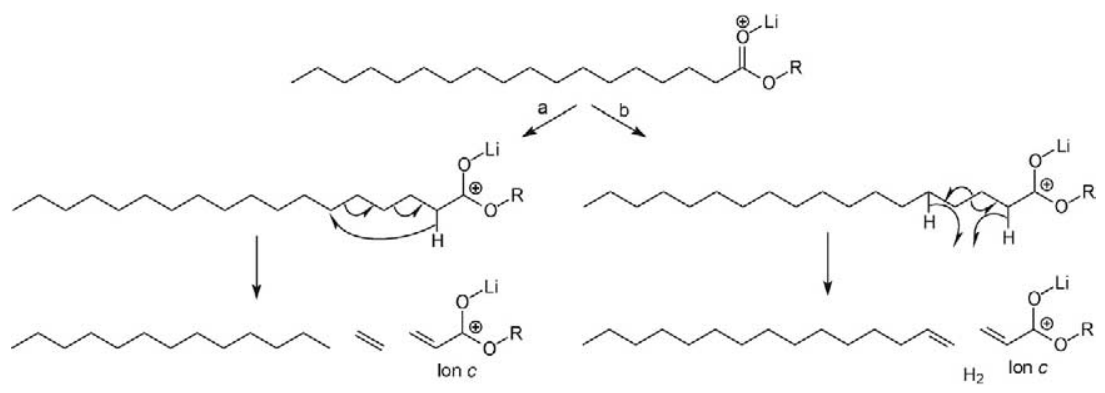

Scheme 4. Proposed mechanisms for the formation of ions such as that at $\mathrm{m} / \mathrm{z} 135$ in the high energy positive ion CID mass spectrum of the $[\mathrm{M}+\mathrm{Li}]^{+}$ion from esters of octadecanoic (stearic) acid.

cated similar hydrogen migrations to account for fragments in the resonance electron capture mass spectra of deuterated palmitic acid. Hydrogen migrations from hydroxy-groups to the carboxy function of hydroxy fatty acid anions have recently been observed by Moe et al.é[57]ébutéinénoneéofétheélatteréthreeéreportsé[55-57], however, was the charge proposed to migrate to the aliphatic chain as proposed here.

The ion of lowest mass of the $\mathrm{C}_{n} \mathrm{H}_{2 n+2}$ high-energy series is $m / z 99$, as can be seen from the spectrum of stearic acidé(Figureé2)épublishedébyéGriffithséetéal.é[40].éOnéthe above charge-associated theory, this ion would result from initial migration of the hydrogen atom at $\mathrm{C} 3$ to the anionic oxygen. Molecular models show that this hydrogen atom is the closest that can be involved in such a reaction and that the hydrogen atom at $\mathrm{C} 2$ cannot approach the charged oxygen close enough to form a bond, thus accounting for the absence of the next potential ion in the series at $m / z$ 85. The low abundance or absence of this ion,édesignatedêC5 [28]é(seeêFigureé3),éinebothétheépositiveéandénegativeéion spectra of fatty acids and their derivatives, has frequently beenécommentedéoné[23,é28,é51]ébuténoéexplanationéhas been proposed. The above charge-assisted mechanism provides an explanation as this reaction could not form the ' $\mathrm{C} 5$ ion because of the inability of the necessary hydrogen atom to migrate to the charge site. If the random, charge-remote mechanism were in operation, one would expect an ion at this position and also one at $\mathrm{m} / \mathrm{z}$ 71. Although there is an ion present at $\mathrm{m} / \mathrm{z} 71$, its formation can be rationalized by the mechanism shown in Scheme 3 (Ion $b$ ) which is consistent with the loss of one hydrogen atom as shown by the deuterium labeling data publishedebyeVoinovéetéel.e[58].

\section{Positive Ions of the $\left[\mathrm{M}-\mathrm{C}_{n} \mathrm{H}_{2 n+2}\right]^{+}$Series}

The proposed charge-assisted mechanism also accounts for the formation of most of the $\left[\mathrm{M}-\mathrm{C}_{\mathrm{n}} \mathrm{H}_{2 \mathrm{n}+2}\right]^{+}$ions in the high-energy spectra of positive ions. Thus, adduction of the acid with an alkali metal results in a resonance-stabilized ion in which one possible structure is that of a tertiary carbonium ion (see Scheme 4). Similar ions result from ionization of the alkali metal salts or alkyl esters. It is clear from the published
spectraéofén-butylépalmitateéionizedéwithélithiumé(Figureê), êhaténêonéformedêbyécleavageéofếheéc-3,4bond ( $m / z$ 135)êséparticularlyéstableđ22,ę3,ę8].éAlthoughưhis ion does not appear to be formed by the above chargeassisted mechanism, its proposed structure of an allylic carbonium ion attests to the high stability of this ion type. Its formation can be rationalized by the mechanism shown in Scheme 4 (Ion $c$ ). The mechanism is consistent with the deuterium-labeling data reported by Nizigiyimanaćeté⿴l.đ23],éwhichéconfirmedAlosséffhydrogen (deuterium) from C-2. However, rather than expulsion of a hydrogen atom and loss of the C4-C16 moiety asééradical,ésé́proposedĐbyêNizigiyimanaéetẹ́l.đ23],êhe reaction is now envisaged as involving the hexacyclic transition state shown in Scheme 4 with loss of neutral, even-electron species, the driving force for the reaction being the formation of the allylic carbonium ion.

Transfer of hydrogen atoms to the charge site from other positions on the aliphatic chain, resulting in the carbonium center migrating to the carbon atom that has lost the hydrogen, accounts for other ions in the $[\mathrm{M}-$ $\left.\mathrm{C}_{\mathrm{n}} \mathrm{H}_{2 \mathrm{n}+2}\right]^{+}$series. Both a 1,4-hydrogen elimination or a hexacyclic hydrogen migration are fully consistent with the deuterium-labeling data presented by Claeys et al. [22],éwhoéshowedéthatéaêhydrogenéatoméwasélostéfrom the C9 position of the lithium adduct of $n$-butyl palmitate during rupture of the $\mathrm{C} 10-\mathrm{C} 11$ bond. However, the proposed charge-assisted mechanism does not require the initial, energetically unfavorable expulsion of a hydrogen atom (odd electron) or the formation of unstabilized radicals as proposed by these investigators.êTheéhydrogenélosséobservedébyéClaeyséetéal.é[22] (Figureé3)é waséalsoéaccompaniedébyéaé pronounced deuterium isotope effect. Similar effects were recorded byéJensenéetéal.é[33]éforétheéspectruméofé7,7,8,8-[ $\left[{ }^{2} \mathrm{H}_{4}\right]-$ palmitic acid, fully consistent with the proposal that the product ions possessed a terminal double bond. A similar structure is incorporated into the product of the charge-assisted mechanism proposed here.

Because kinetic deuterium isotope effects were observed for cleavage of the $\mathrm{C}-\mathrm{H}$ bond during the chain cleavage reaction, a similar effect might also be expected to occur for cleavages in which hydrogen from the deuterated site is proposed to migrate to the carboxy terminus in the first stage of the reaction. How- 


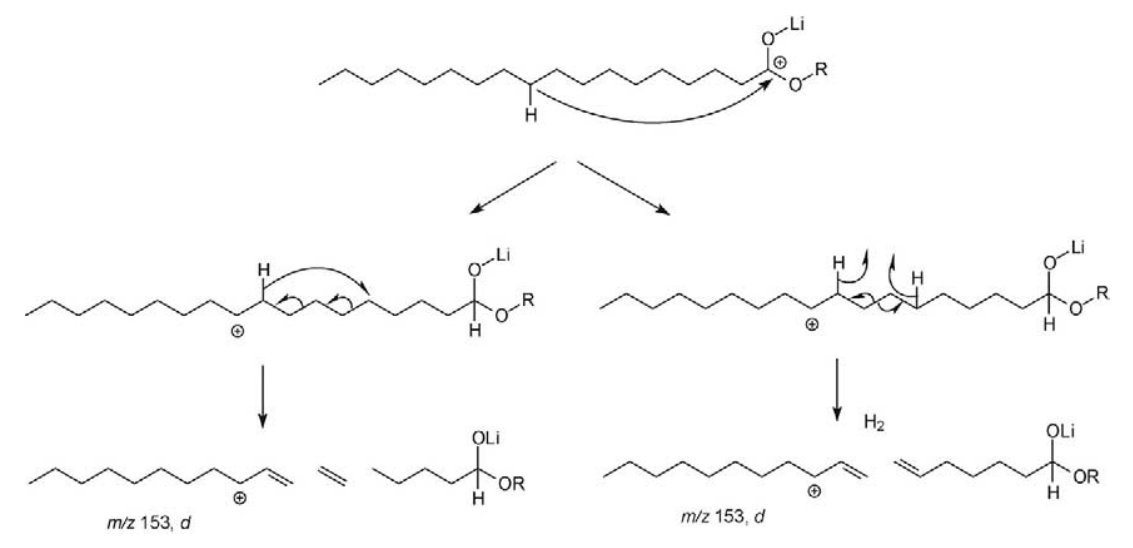

Scheme 5. Proposed mechanism for the formation of a hypothetical ion having the charge on the fragment not containing the carboxy function; shown for fragmentation of the $\left[\mathrm{M}+\mathrm{Li}^{+}\right.$ion from the ester of octadecanoic (stearic) acid.

ever, such a deuterium isotope effect is not seen and could argue against the occurrence of the chargeassisted process. On the other hand, this first hydrogen transfer to the ionic site is of a $\mathrm{H}^{-}$or proton, depending on the nature of the spectrum, rather than of a hydrogen atom (single electron), and there is evidence that ionic hydrogen transfers do not show significant deuterium isotopeéeffectsé[59].élnéaddition,étheéreactionéinvolves bond formation to the deuterium atom within the same ion, a process that can exhibit an opposing isotope effect. Thus, the absence of a kinetic isotope effect may be attributable to the fact that the electron pair to the hydrogen atom is not broken and could, in fact, support the proposal that the hydrogen migrates with an electron pair or as a proton.

Once the charge has migrated to the center of the aliphatic chain, it is conceivable that the reaction causing chain rupture could occur on either side of the charge site; an example of such a theoretical reaction occurring to the carboxy side of the charge is shown in Scheme 5 to produce an ion at $m / z 153$, (d). However, no ions are present at the mass of the expected products of such a cleavage, suggesting that the charge remains associated with the carboxy side of the molecule and that the two-stage reaction pictured above is, in fact, a concerted process as shown in Scheme $\mathbf{6}$ with the charge partially associated with the carboxy function during the chain-cleavage reaction. This partial localization of the charge on the carboxy group during the fragmenta- tion process presumably accounts for the preferential retention of the charge on the ion containing this group rather than with the unsubstituted terminus.

\section{Other Ions}

The above mechanism only accounts for one series of ions that appear in the spectra of these compounds. It is apparent, however, that other ions, notably those with the composition $\left[\mathrm{M}-\mathrm{C}_{\mathrm{n}} \mathrm{H}_{2 \mathrm{n}+1}\right]^{+}$are present to varying extents depending on factors such as ion energy. Thus, foréexample,éClaeyséetéal.é[28]énotedéthatésuchéanéion series was also present in the positive ion high energy spectra of alkali metal adducted acids; we have found that, in the low energy spectra of these compounds, several other processes also occur, although with low probability, to give spectra that contain ions at other masses such as [M $\left.-\mathrm{C}_{\mathrm{n}} \mathrm{H}_{2 \mathrm{n}+4}\right]$. Formation of several of these ions can also be accounted for by mechanisms similar to the charge-assisted mechanism presented in this paper, as discussed below.

The $\left[\mathrm{M}-\mathrm{C}_{\mathrm{n}} \mathrm{H}_{2 \mathrm{n}+1}\right]^{+\cdot}$ ion series are radical ions and do not involve net expulsion of a hydrogen molecule $\left(\mathrm{H}_{2}\right)$ to give the neutral species as seen with the $[\mathrm{M}-$ $\left.\mathrm{C}_{\mathrm{n}} \mathrm{H}_{2 \mathrm{n}+2}\right]^{+} \mathrm{e}_{\text {ions.éGriffithséetéal.é[40]éinvokedétheéfirst }}$ stageéofétheémechanisméproposedøyêWysockiéndêRoss [46]é involvingé homolyticé cleavageé ofé aé $C$ - Cébond followed by a $\beta$-hydrogen elimination to form an unsaturated, closed-shell product ion, in order to account
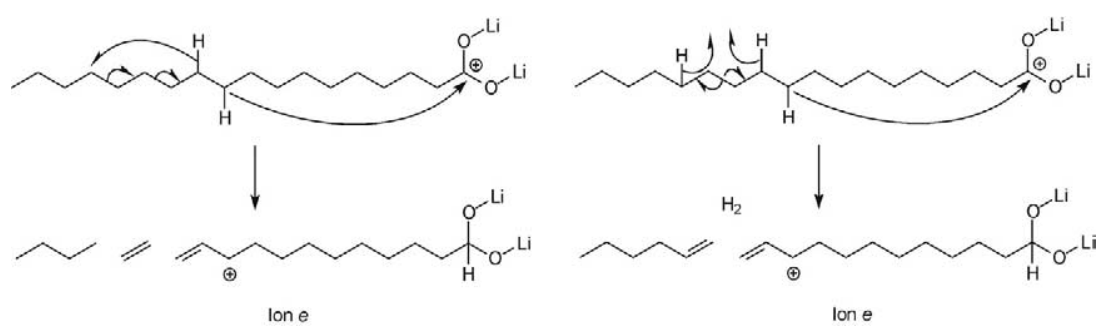

Scheme 6. Proposed concerted mechanisms for the formation of $\left[\mathrm{M}-\mathrm{C}_{n} \mathrm{H}_{2 n+2}\right]^{+}$ions in the high energy positive ion CID mass spectrum of the $[\mathrm{M}-\mathrm{H}+2 \mathrm{Li}]^{+}$ion from octadecanoic (stearic) acid. 

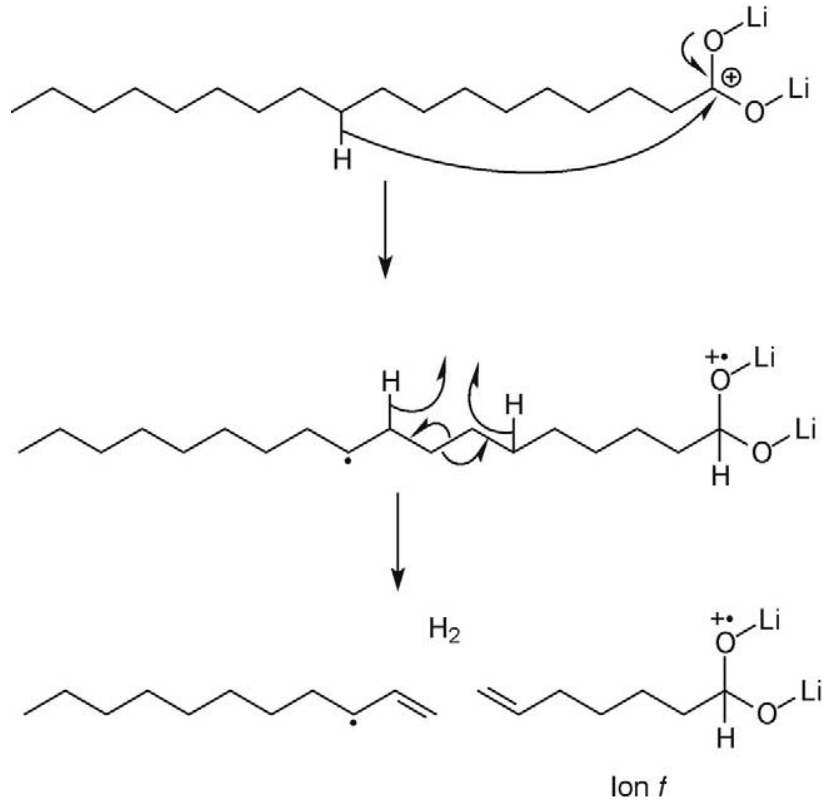

Scheme 7. Proposed mechanisms for the formation of the radical cations from the $\left[\mathrm{M}-\mathrm{C}_{\mathrm{n}} \mathrm{H}_{2 \mathrm{n}+1}\right]^{+\cdot}$ series in the high energy positive ion CID mass spectrum of the $[\mathrm{M}-\mathrm{H}+2 \mathrm{Li}]^{+}$ion from octadecanoic (stearic) acid.

for these ions. However, this mechanism does not account for the distribution of ions of this type and involves the thermodynamically unfavorable homolytic cleavage of a stable $\mathrm{C}-\mathrm{C}$ bond to give two less stable radicals. The more energetically favorable mechanism proposed here is related to the charge-assisted process and envisages hydrogen migration from the carbon chain to the charge site as before, but as a hydrogen atom (one electron) rather than as a proton as in Schemes 4 and $\mathbf{5}$. Thus, hydrogen migration from the aliphatic chain to the charged oxygen atom followed by a 1,4-hydrogen elimination (or hexacyclic hydrogen migration), as shown in Scheme 7 can account for the formation of these ions. Both radicals in the resulting distonic ion $(f)$ and neutral particle are stabilized by resonance, thus providing the driving force.

Formation of ions of the type $\left[\mathrm{M}-\mathrm{C}_{\mathrm{n}} \mathrm{H}_{2 n}\right]^{+}$involves

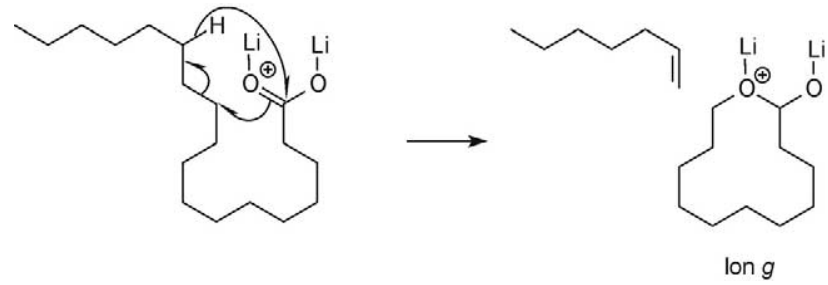

Scheme 8. Proposed mechanisms for the formation of ions from the $\left[\mathrm{M}-\mathrm{C}_{\mathrm{n}} \mathrm{H}_{2 \mathrm{n}}\right]^{+}$series in the low energy positive ion CID mass spectrum of octadecanoic (stearic) acid.

net transfer of a hydrogen atom from the leaving fragment to the observed fragment ion, a process that could involve formation of a double bond in the neutral fragment. A suggested mechanism that avoids the postulation of radical or hydrogen atom elimination is shown in Scheme 8. It involves abstraction of a hydrogen atom to the charge site, as before, leaving a radical site on the carbon chain. This site initiates cleavage on the carboxy side of the radical site to give a double bond in the fragment and with bond formation between the new radical site on the chain and the carboxy site (Ion $g$ ). The process, as above, is conceived as being concerted. A similar reaction could be proposed for equivalent ions in the negative ion spectrum.

\section{Monounsaturated Fatty Acids}

The CID spectra of both the $[\mathrm{M}-\mathrm{H}]^{-}$and $[\mathrm{M}+$ Cation] ${ }^{+}$ions from monounsaturated compounds again appear very similar to those of the positive ion EI spectraéoféderivativesésuchéasétheépicolinyléestersé[10é 13],éthusésuggestingéthatésimilaréfragmentationémechanisms are involved. The pattern of ions can also be explained by the charge-assisted process as described in this paper. The increased relative abundance of the two ions at higher mass compared with those weak ions caused by the presence of unsaturation can be rationalized by involvement of the allylic hydrogen atoms, either in the initial hydrogen migration to the charge site, or to their involvement in the subsequent hydrogen

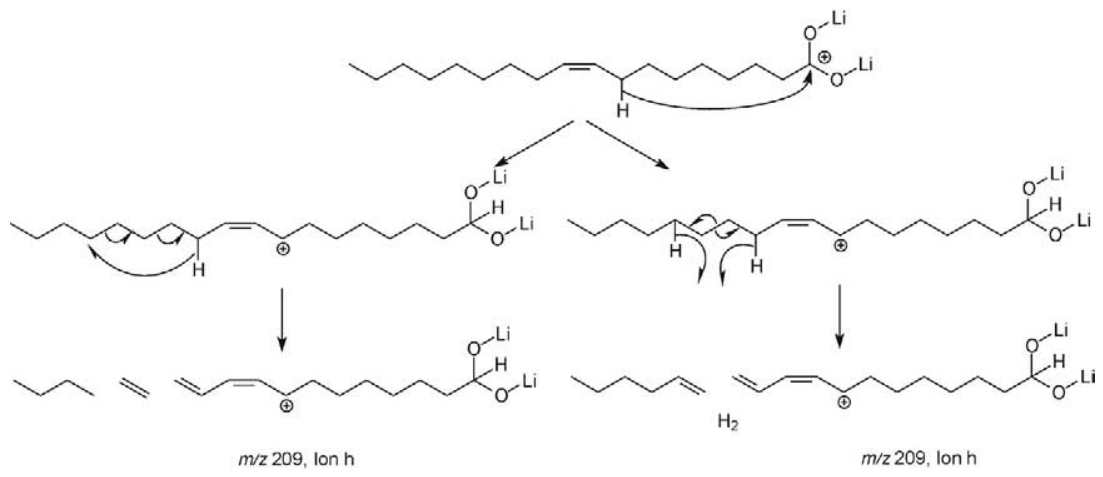

Scheme 9. Proposed mechanisms for the formation of the ion involving cleavage of the distal vinylic bond in the high energy positive ion CID mass spectrum of the $[\mathrm{M}-\mathrm{H}+2 \mathrm{Li}]^{+}$ion from $\Delta^{9}$-octadecenoic (oleic) acid. 


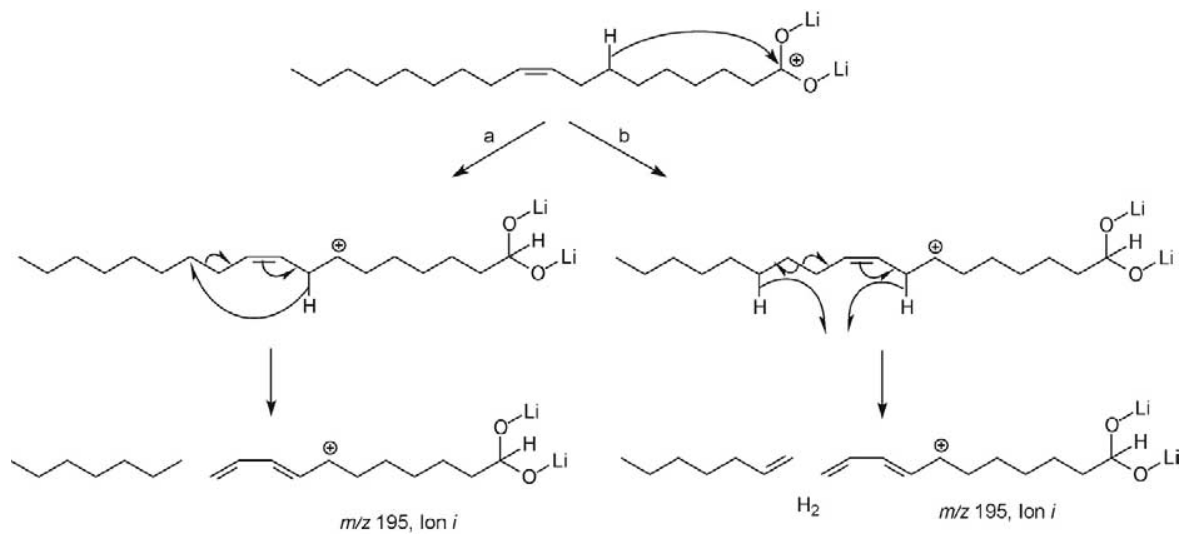

Scheme 10. Proposed mechanisms for the formation of the ion involving cleavage of the distal allylic bond in the high energy positive ion CID mass spectrum of the $[\mathrm{M}-\mathrm{H}+2 \mathrm{Li}]^{+}$ion from $\Delta^{9}$-octadecenoic (oleic) acid.

elimination. Thus, cleavage of the $\mathrm{C} 12-\mathrm{C} 13$ bond of the [Mé-éHé +é2Li] $]^{+e ́}$ froméoleicéacidétoégiveétheé'C12 fragmenté( $m / z$ 209,élonéh, Figureélb)éiséenvisagedéas proceeding as shown in Scheme 9 and to involve migrations of both allylic hydrogen atoms. The spectrum of the lithium adduct of butyl $\left[11,11-{ }^{2} \mathrm{H}_{2}\right]$-oleate [22] éshowséméclearêsotopeéeffecténdéoneémasséunitéshift for the formation of this ion, supporting the proposal.

Cleavage of the $\mathrm{C} 11-\mathrm{C} 12$ bond to produce a similarlyéconjugatedéioné $(m / z$ 195,éFigureé1b,élonéi)émust involve migration of the double bond as seen in similar rearrangementséunderéEléconditionsé[10,é13].éTheéproposed mechanism is shown in Scheme $\mathbf{1 0}$ with elimination of the allylic hydrogen from C8 involved in the second stage of the reaction. There is no involvement of the hydrogen atoms from $\mathrm{C} 11$, consistent with the shift of two mass units in the spectrum of butyl $\left[11,11^{2} \mathrm{H}_{2}\right]-$ oleateé[22].éAé1,4-hydrogenéeliminationéwouldénotébe possible in this fragmentation as loss of the hydrogen atoms from $\mathrm{C} 8$ and $\mathrm{C} 11$ would not result in $\mathrm{C}-\mathrm{C}$ bond cleavage. It is conceivable, however, that a 1,6-hydrogen elimination could occur as shown in Scheme 10, Path $\mathrm{b}$, but this is inconsistent with the spectrum of $\left[11,11-{ }^{2} \mathrm{H}_{2}\right]$-cis-7-dodecenoic acid published by Contado

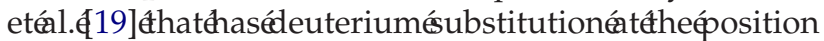
of the non-allylic hydrogen atom. If a 1,6-hydrogen elimination were to occur, a deuterium isotope effect would be expected. However, none was observed.

Cleavage of the $\mathrm{C} 11-\mathrm{C} 12$ bond also gives rise to a prominent radical ion of the $\left[\mathrm{M}-\mathrm{C}_{\mathrm{n}} \mathrm{H}_{2 \mathrm{n}+1}\right]$ éseriesé 28 , 40]éthat,éinésomeéspectra,énotablyéthatéofétheésodium adductế[28],éexceedsétheéabundanceéofétheécorresponding $\left[\mathrm{M}-\mathrm{C}_{\mathrm{n}} \mathrm{H}_{2 \mathrm{n}+1}\right]$ êon.éClaeyséetél.đđ28] thaveéproposed a mechanism involving formation of a bi-radical intermediate, alkyl migration, and radical elimination. Alkyl migration was also proposed to account for ions in the resonance electron capture mass spectra of unsaturated

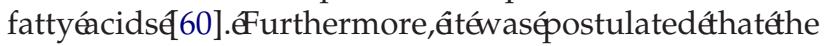
product distonic radical cation proposed by Claeys et al. [28]éeliminatedéếfurtherêhydrogenéatométoégiveétheâon from the $\left[\mathrm{M}-\mathrm{C}_{\mathrm{n}} \mathrm{H}_{2 \mathrm{n}+1}\right]$ series. The charge-assisted mechanism proposed here to account for the $\mathrm{C} 11-\mathrm{C} 12$ bond cleavage is simpler and is shown in Scheme 11. An initial hydrogen atom (one electron) transfer of the allylic hydrogen from C8 to the charged carboxy function leaves a stabilized allylic radical on the aliphatic chain. Radical-induced cleavage of the chain accompanied by migration of the double bond results in elimination of an alkyl radical and formation of the conjugated radical cation $j$.

The mechanism proposed for formation of the $\mathrm{C}_{n} \mathrm{H}_{2 n+2}$ ion to the lower mass side of the double bond of monounsaturated fatty acids involving cleavage of

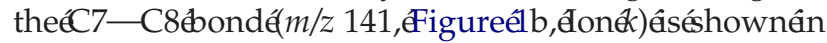
Scheme 12. No deuterium isotope effect was seen in the spectrum of butyl $\left[11,11-{ }^{2} \mathrm{H}_{2}\right]$-oleateé[22]éindicatingéno involvement of the $\mathrm{C}-11$ hydrogen atom. However the
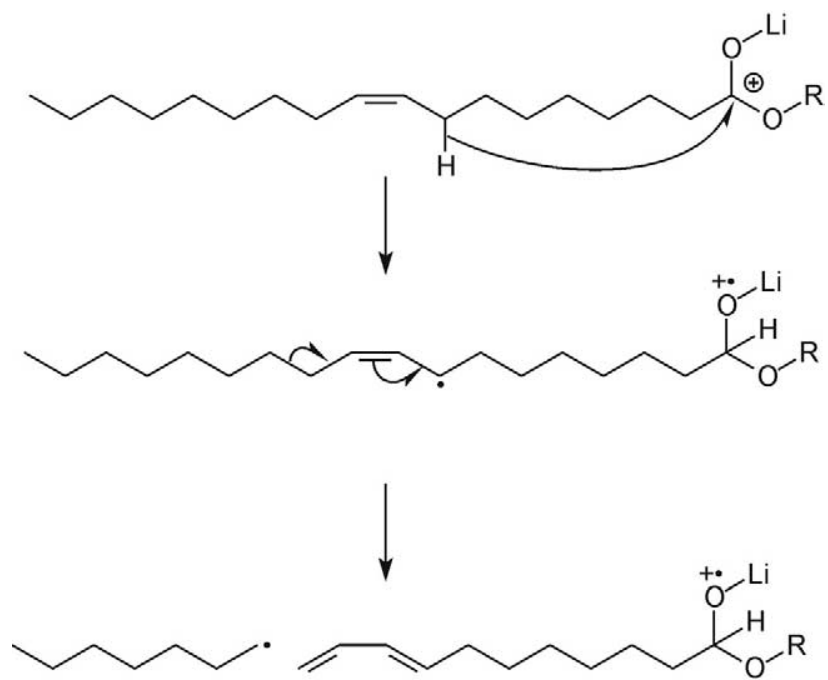

Ion $j$

Scheme 11. Proposed mechanisms for the formation of the ions of the $\left[\mathrm{M}-\mathrm{C}_{\mathrm{n}} \mathrm{H}_{2 \mathrm{n}+1}\right]^{+\cdot}$ series involving cleavage of the distal vinylic bond in the high energy positive ion mass spectrum of the $[\mathrm{M}-\mathrm{H}+2 \mathrm{Li}]^{+}$ion from $\Delta^{9}$-octadecenoic (oleic) acid. 


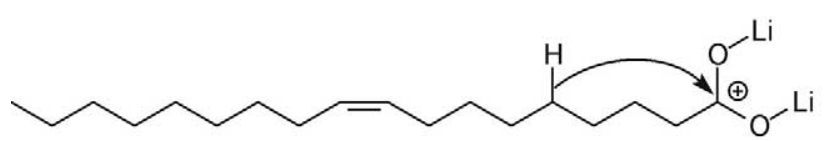

$\downarrow$
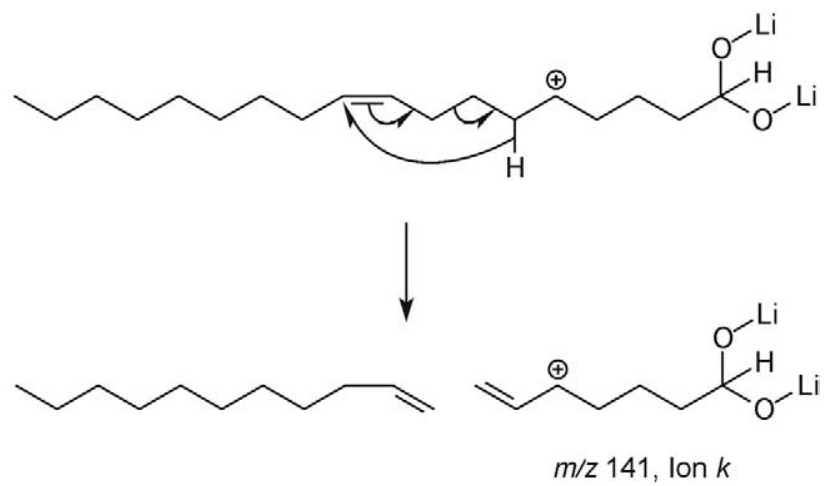

Scheme 12. Proposed mechanism for the formation of the ion involving cleavage of the proximal allylic bond in the high energy positive ion CID mass spectrum of the $[\mathrm{M}-\mathrm{H}+2 \mathrm{Li}]^{+}$ion from $\Delta^{9}$-octadecenoic (oleic) acid.

spectrum of the lithium salt/adduct of $\left[4,4-{ }^{2} \mathrm{H}_{2}\right]$-cis-7dodecenoicécidépublished byéContadoétél.ę19],éwhich has deuterium in a comparable position relative to the double bond as the other migrating hydrogen, provides clear mass shift and relative abundance data to support this mechanism.

\section{Conclusions}

The charge-assisted mechanisms proposed here to account for the ions occurring in the high energy CID spectra of fatty acids and their analogs provide an additional mechanism to the charge-remote fragmentations proposed earlier to account for the occurrence of these ions. The mechanism provides an explanation as to why the CID spectra closely resemble the spectra of fatty acids derivatized with nitrogenous heterocycles and is in keeping with proposals of other investigators who believe that charge is somehow involved in the formation of these ions. It is not proposed that the charge-assisted mechanism is the only process leading to $\left[\mathrm{M}-\mathrm{C}_{\mathrm{n}} \mathrm{H}_{2 \mathrm{n}+2}\right.$ ]-type fragments; charge remote reactions could also occur and, indeed, for some polyunsaturated compounds where the charge-remote process leads to stable, conjugated species, this may well be the case. However, there is ample evidence that long-range hydrogen migrations occur in these compounds under various conditions such as electron impact, and that hexacyclic hydrogen migrations occur along the aliphaticéchainé[54,é61].éConsequently,éitéisépossibleéthat the charge-assisted mechanism proposed here could be the dominant mechanism exhibited by these compounds under high energy conditions.

\section{Acknowledgments}

The author thanks Professor R. A. Dwek, Director of the Glycobiology Institute, for his help and encouragement.

\section{References}

1. Niehaus, W. G., Jr.; Ryhage, R. Determination of double bond positions in polyunsaturated fatty acids by combination gas chromatography-mass spectrometry. Anal. Chem. 1968, 40, 1840-1847.

2. Capella, P.; Zorzut, C. M. Determination of double bond position in monounsaturated fatty acid esters by mass spectrometry of their trimethylsilyloxy derivatives. Anal. Chem. 1968, 40, 1458-1463.

3. Yu, Q.; Zhang, J.; Huang, Z. A novel approach to double bond location in long-chain olefinic acids: The mass spectra of 2-alkenylbenzoxazoles. Biomed. Environ. Mass Spectrom. 1986, 13, 211-216.

4. Andersson, B. A.; Holman, R. T. Pyrrolidides for mass spectrometric determination of the position of the double bond in monounsaturated fatty acids. Lipids 1974, 9, 185-190.

5. Andersson, B. A.; Heimermann, W. H.; Holman, R. T. Comparison of pyrrolidides with other amides for mass spectral determination of structure of unsaturated fatty acids. Lipids 1974, 9, 443-449.

6. Andersson, B. A.; Holman, R. T. Mass spectrometric localization of methyl branching in fatty acids using acylpyrrolidines. Lipids 1975, 10, 716-718.

7. Andersson, B. A. Mass Spectrometry of fatty acid pyrrolidides. Prog. Chem. Fats Other Lipids 1978, 16, 279-308.

8. Vetter, W.; Walther, W. Preparation of pyrrolidides from fatty acids via trimethylsilyl esters for gas chromatographic mass spectrometric analysis. J. Chromatogr. 1990, 513, 405-407.

9. Vetter, W.; Meister, W.; Oesterhelt, G. 2-Alkylimidazoline derivative to control fatty acid fragmentation upon electron impact and electrospray iomization. J. Mass Spectrom. 1998, 33, 461-472.

10. Harvey, D. J. Picolinyl esters as derivatives for the structural determination of long-chain branched and unsaturated fatty acids. Biomed. Mass Spectrom. 1982, 9, 33-38.

11. Harvey, D. J. Picolinyl derivatives for the structural determination of fatty acids by mass spectrometry: Applications to polyenoic acids, hydroxy-acids, di-acids, and related compounds. Biomed. Mass Spectrom. 1984, 11, 340-347.

12. Harvey, D. J. Picolinyl derivatives for the characterisation of cyclopropane fatty acids by mass spectrometry. Biomed. Mass Spectrom. 1984, 11, 187-192.

13. Harvey, D. J. Mass spectrometry of picolinyl and other nitrogen-containing derivatives of lipids. In Advances in Lipid Methodology-One; Christie, W. W., Ed.; The Oily Press: Ayr, 1992; 19-80.

14. Minnikin, D. E. Location of double bonds and cyclopropane rings in fatty acids by mass spectrometry. Chem. Phys. Lipids 1978, 21, 213

15. Adams, J.; Gross, M. L. Energy requirements for remote charge site ion decompositions and structural information from collisional activation of alkali metal cationized fatty alcohols. J. Am. Chem. Soc. 1986, 108, 6915-6921.

16. Adams, J.; Gross, M. L. Tandem mass spectrometry for collisional activation of alkali metal-cationized fatty acids: A method for determining double bond location. Anal. Chem. 1987, 59, 1576-1582.

17. Adams, J.; Gross, M. L. Charge-remote fragmentations of closed-shell ions. A thermolytic analogy. J. Am. Chem. Soc. 1989, 111, 435-440.

18. Crockett, J. S.; Gross, M. L.; Christie, W. W.; Holman, R. T. Collisional activation of a series of homoconjugated octadec- 
adienoic acids with fast atom bombardment and tandem mass spectrometry. J. Am. Soc. Mass Spectrom. 1990, 1, 183-191.

19. Contado, M. J.; Adams, J.; Jensen, N. J.; Gross, M. L. A charge-remote allylic cleavage reaction: Mechanistic possibilities. J. Am. Soc. Mass Spectrom. 1991, 2, 180-183.

20. Contado, M. J.Adams, J. Collision-induced dissociations and B/E linked scans for structural determination of modified fatty acid esters. Anal. Chim. Acta 1991, 246, 187-197

21. Claeys, M.; Ven den Heuvel, H. Radical processes in remote charge fragmentations of lithium-cationized long-chain alkenyl and alkadienyl salicylic acids. Biol. Mass Spectrom. 1994, 23, 20-26.

22. Claeys, M.; Nizigiyimana, L.; Van den Heuvel, H.; Derrick, P. J. Mechanistic aspects of charge-remote fragmentation in saturated and mono-unsaturated fatty acid derivatives. Evidence for homolytic cleavage. Rapid Commun. Mass Spectrom. 1996, 10, 770-774.

23. Nizigiyimana, L.; Rajan, P. K.; Haemers, A.; Claeys, M.; Derrick, P. J. Mechanistic aspects of high-energy collisioninduced dissociation proximate to the charge in unsaturated fatty acid $n$-butyl esters cationized with lithium. Evidence for hydrogen radical removal. Rapid Commun. Mass Spectrom. 1997, 11, 1808-1812.

24. Cheng, C.; Giblin, D.; Gross, M. L. Structural determination of oxofatty acids by charge-remote fragmentations. J. Am. Soc. Mass Spectrom. 1998, 9, 216-224.

25. Cheng, C.; Gross, M. L. Fragmentation mechanisms of oxofatty acids via high-energy collisional activation. J. Am. Soc. Mass Spectrom. 1998, 9, 620-627.

26. Claeys, M.; Nizigiyimana, L.; Van Den Heuvel, H. Mechanistic aspects of charge-remote fragmentation in saturated and unsaturated fatty acid derivatives. Adv. Mass Spectrom. 1998, 14, A062320/062321-A062320/062329.

27. Hsu, F.-F.; Turk, J. Distinction among isomeric unsaturated fatty acids as lithiated adducts by electrospray ionization mass spectrometry using low energy collisionally activated dissociation on a triple stage quadrupole instrument. J. Am. Soc. Mass Spectrom. 1999, 10, 600-612.

28. Claeys, M.; Nizigiyimana, L.; Van den Heuvel, H.; Vedernikova, I.; Haemers, A. Charge-remote and charge-proximate fragmentation processes in alkali-cationized fatty acid esters upon high-energy collisional activation. A new mechanistic proposal. J. Mass Spectrom. 1998, 33, 631-643.

29. Davoli, E.; Gross, M. L. Charge remote fragmentation of fatty acids cationized with alkaline earth metal ions. J. Am. Soc. Mass Spectrom. 1990, 1, 320-324.

30. Chang, Y. S.; Watson, J. T. Charge-remote fragmentation during FAB-CAD-B/E linked-scan mass spectrometry of (aminoethyl)triphenylphosphonium derivatives of fatty acids. J. Am. Soc. Mass Spectrom. 1992, 3, 769-775.

31. Deterding, L. J.; Gross, M. L. Fast-atom-bombardment and tandem mass spectrometry for determining structures of fatty acids as their picolinyl ester derivatives. Anal. Chim. Acta 1987, 200, 431-445.

32. Deterding, L. J.; Gross, M. L. Tandem mass spectrometry for identifying fatty acid derivatives that undergo charge-remote fragmentations. Org. Mass Spectrom. 1988, 23, 169-177.

33. Jensen, N. J.; Tomer, K. B.; Gross, M. L. Gas-phase ion decompositions occurring remote to a charge site. J. Am. Chem. Soc. 1985, 107, 1863-1868.

34. Jensen, N. J.; Tomer, K. B.; Gross, M. L. Collisional activation decomposition mass spectra for locating double bonds in polyunsaturated fatty acids. Anal. Chem. 1985, 57, 2018-2021.

35. Jensen, N. J.; Gross, M. L. Fast atom bombardment and tandem mass spectrometry for determining iso- and anteiso fatty acids. Lipids 1986, 21, 362-365.
36. Antoine, M.; Adams, J. Implication of the charge site in charge-remote fragmentations. J. Am. Soc. Mass Spectrom. 1992, 3, 776-778.

37. Yang, Y.; Griffiths, W. J.; Lindgren, J. Å.; Sjövall, J. Liquid chromatography/mass spectrometry with collision-induced dissociation of arachidonic acid metabolites derivatized with aminobenzenesulphonic acid. Rapid Commun. Mass Spectrom. 1995, 9, 289-299.

38. Kerwin, J. L.; Wiens, A. M.; Ericsson, L. H. Identification of fatty acids by electrospray mass spectrometry and tandem mass spectrometry. J. Mass Spectrom. 1996, 31, 184-192.

39. Griffiths, W. J.; Brown, A.; Reimendal, R.; Yang, Y.; Zhang, J.; Sjövall, J. A comparison of fast-atom bombardment and electrospray as methods of ionization in the study of sulphatedand sulphonated lipids by tandem mass spectrometry. Rapid Commun. Mass Spectrom. 1996, 10, 1169-1174.

40. Griffiths, W. J.; Yang, Y.; Lindgren, J. Å.; Sjövall, J. Charge remote fragmentation of fatty acid anions in $400 \mathrm{eV}$ collisions with xenon ions. Rapid Commun. Mass Spectrom. 1996, 10, 21-28.

41. Cheng, C.; Pittenauer, E.; Gross, M. Charge-remote fragmentations are energy-dependent processes. J. Am. Soc. Mass Spectrom. 1998, 9, 840-844.

42. Claeys, M.; Nizigiyimana, L.; Van Den Heuvel, H., Mass spectrometry in the structure determination of long-chain fatty acid derivatives. In Fundamentals and Applications of Gas Phase Ion Chemistry; Jennings, K. R., Ed.; Kluwer Scientific Publishers: Amsterdam, 1999; pp 149-163.

43. Caldwell, K. A.; Gross, M. L. Structure determination of lipids: comparison of classical methods and new approaches involving charge-remote fragmentation. In Mass Spectrometry in the Biological Sciences: A Tutorial; Gross, M. L., Ed.; Kluwer Scientific Publishers: Amsterdam, 1992; pp 413-425.

44. Gross, M. L. Charge-remote fragmentation: an account of research on mechanisms and applications. Int. J. Mass Spectrom. 2000, 200, 611-624.

45. Cheng, C.; Gross, M. L. Applications and mechanisms of charge-remote fragmentation. Mass Spectrom. Rev. 2000, 19, $398-420$.

46. Wysocki, V. H.; Ross, M. M. Charge-remote fragmentation of gas-phase ions: Mechanistic and energetic considerations in the dissociation of long-chain functionalized alkanes and alkenes. Int. J. Mass Spectrom. Ion Processes 1991.

47. Spiteller, G.; Spiteller-Friedmann, M.; Houriet, R. Elucidation of mass-spectroscopic fragmentation mechanisms by use of cold ion sources and low-energy electrons. I. Aliphatic esters. Monatsh. Chem. 1966, 97, 121-128.

48. Kraft, M.; Spiteller, G. $\beta, \alpha$-Cleavage of carbonyl compounds and derivatives as a general principal decomposition reaction in the mass spectrometer. Org. Mass Spectrom. 1969, 2, 541-546.

49. Tulloch, A. P.; Hogge, L. R. Investigation of the formation of $\mathrm{MH}^{+}$and other ions in the mass spectrum of methyl decanoate using specifically deuterated decanoates. Chem. Phys. Lipids $1985,37,271-281$.

50. Vidavsky, I.; Chorush, R. A.; Longevialle, P.; McLafferty, F. W. Functional group migration in ionized long-chain compounds. J. Am. Chem. Soc. 1994, 116, 5865-5872.

51. Huysmans, L.; Nizigiyimana, L.; Van den Heuvel, H.; Claeys, M. Charge-remote molecular hydrogen removal in protonated and alkali-cationized long-chain fatty acid esters upon cesium ion bombardment. Int. J. Mass Spectrom. 1999, 188, 39-52.

52. Weast, R. C.; Astle, M. J. Bond strengths in polyatomic molecules. In CRC Handbook of Chemistry and Physics; Weast, R. C.; Astle, M. J., Eds.; CRC Press: Boca Raton, 1982; p F191.

53. Cordero, M. M.; Wesdemiotis, C. Characterization of the neutral products formed upon the charge-remote fragmentation of fatty acid ions. Anal. Chem. 1994, 66, 861-866. 
54. Harvey, D. J. Absence of the McLafferty rearrangement ions in the tandem mass spectra of carboxylic acid esters. Org. Mass Spectrom. 1993, 28, 287-288.

55. Laprévote, O.; Faucheur, N.; Serani, L.; Das, B. C. Involvement of intermediate radical ions in charge-remote fragmentation processes. Adv. Mass Spectrom. 1998, 14, A015290/015291A015290/015215.

56. Voinov, V. G.; Claeys, M. Charge-remote fragmentation of fatty acid molecular anions: Examination by using resonance electron capture mass spectrometry. Int. J. Mass Spectrom. 2000, 198, 23-32.

57. Moe, M. K.; Strøm, M. B.; Jensen, E.; Claeys, M. Negative electrospray ionization low-energy tandem mass spectrometry of hydroxylated fatty acids: a mechanistic study. Rapid Commun. Mass Spectrom. 2004, 18, 1731-1740.
58. Voinov, V. G.; Van den Heuvel, H.; Claeys, M. Resonant electron capture mass spectrometry of free fatty acids: examination of ion structures using deuterium-labeled fatty acids and collisional activation. J. Mass Spectrom. 2002, 37, 313-321.

59. Scheiner, S. Calculation of isotope effects from first principles. Biochim. Biophys. Acta 2000, 1458, 28-42.

60. Voinov, V. G.; Claeys, M. Charge-remote fragmentation characteristics of monounsaturated fatty acids in resonance electron capture: Differentiation between cis and trans isomers. Int. J. Mass Spectrom. 2001, 2205, 57-64.

61. Dinh-Nguyen, N.; Ryhage, R.; Stallberg-Stenhagen, S.; Stenhagen, E. Mass spectrometric studies. VIII. A study of the fragmentation of normal long-chain methyl esters and hydrocarbons under electron impact with the aid of D-substituted compounds. Arkiv Kemi. 1961, 18, 393-399. 